Doi: 10.22478/ufpb.1983-1579.2018v1n11.34639 http://periodicos.ufpb.br/ojs2/index.php

\section{CURRÍCULO: um artefato sócio-histórico-cultural}

CURRICULUM: a socio-historical and cultural artifact.

Patricia Teixeira Tavano

Maria Isabel de Almeida²

Resumo: Este ensaio busca recuperar e sistematizar os conceitos de currículo, articulando-os com os elementos que se entremeiam na construção de um currículo educacional. Partindo da concepção de um currículo como artefato sócio-histórico-cultural e recuperando a origem do termo e das formas de utilização educacional do termo, se descreve o movimento de compreender como as relações de poder e estabelecimento dos territórios se articula aos espaços e lugares, permeando e determinando as comunidades disciplinares e epistêmicas na consolidação de um documento que é ao mesmo tempo determinador e determinado, influenciado e influenciador. O currículo como construtor de identidades emerge, pontuando sua influência e poder de aculturação dos que com ele se envolvem.

Palavras-chave: Currículo. Artefato sócio-históricocultural. Espaço e Lugar. Território curricular.
Abstract: This essay seeks to recover and systematize the concepts of curriculum, articulating them with the elements which is comprised in the construction of an educational curriculum. Starting from the conception of a resume as a socio-historical and cultural artifact and recovering the origin of the term and of the ways in which the educational term, narrate the movement of understanding how power relations and estabilishment of the territories are dovetail to the spaces and places, permeating and determining disciplinary and epistemic communities in the consolidation of a document which is both particular and determined influenced and influencer. The curriculum as a builder of identities emerges, punctuating your influence and power of acculturation of that with him involved.

Key-words: Curriculum. Socio-historical and cultural artifact. Space and Place. Curricular territory.

\section{INTRODUÇÃO}

Conceituar currículo no âmbito educacional pode ser tarefa árdua, pois assim como o próprio currículo, a conceituação deste artefato está mediada por concepções de sociedade, de educação, de cultura, distintos em cada grupo que o estuda e o defende, suscitando definições balizadas conforme a contextualização, ou conforme a moldura ${ }^{3}$, dando ao artefato camadas e possibilidades de interpretação e compreensão diversas. Lopes e Macedo (2011) sinalizam para essa dificuldade e partem da premissa de que

[...] não é possível responder "o que é currículo" apontando para algo que the é intrinsecamente característico, mas apenas para acordos de sentidos de tal termo, sempre parciais e localizados historicamente. Cada "nova definição" não é apenas uma

\footnotetext{
${ }^{1}$ Doutorado em Educação pela Universidade de São Paulo, Atualmente é Professora da Universidade Federal do Mato Grosso do Sul. E-mail: patricia@tavano.net. Orcid: https://orcid.org/0000-0002-3145-7818.

${ }^{2}$ Doutora em Didática pela Faculdade de Educação da Universidade de São Paulo (FEUSP) e Livre-docente da Faculdade de Educação da USP. E-mail: mialmei@usp.br. Orcid: https://orcid.org/0000-0003-2506-2972.

3 “Moldura" é uma metáfora utilizada por Veiga-Neto para explicar como as concepções de sociedade, cultura e educação se relacionam e compõem com as concepções de currículo, e os níveis de olhar necessários para que analisemos e compreendamos essas relações e composições. Citando o autor:

"O uso da metáfora da moldura é útil. Ela nos ajuda a compreender que, assim como ao examinarmos um quadro tanto podemos nos ater à pintura em si quanto podemos levar nosso olhar para além dela e perguntar sobre sua relação com as demais obras daquele artista - ou indo além, perguntar sobre até mesmo as condições concretas em que ela foi produzida" (VEIGA-NETO, 2011, p. 60).
} 
nova forma de descrever o objeto currículo, mas parte de um argumento mais amplo no qual a definição se insere (LOPES; MACEDO, 2011, p. 19-20, destaque das autoras).

Convencionalmente, as definições de eventos nas ciências naturais partem dos pontos de contato e similaridade entre fatos, ocorrências, procedimentos para estabelecer uma regra geral, chegando-se ao que seria a definição de tal evento. Com currículo não é possível proceder desta forma para se chegar a uma definição, como as autoras sinalizam, pois, o que se encontra nessa busca são sentidos, que apenas se fazem perceber quando lidos e compreendidos vinculados a um contexto mais amplo, constituído historicamente, reforçando a dimensão da moldura, que nos leva a refletir sobre as condições de produção, mas também sobre as condições de exibição, de proposição, de organização, entre outras.

Moreira (2011) também coloca esta dificuldade, e nos indica que

as divergências refletem problemas complexos, fundamentalmente por se tratar de um conceito que: (a) é uma construção cultural, histórica e socialmente determinada; e (b) se refere sempre a uma "prática" condicionadora do mesmo e de sua teorização (MOREIRA, 2011, p.11-12, destaque do autor).

Reforçando a concepção de currículo como uma construção cultural, histórica e social, o autor nos indica a complexidade do objeto que traz em sua conceituação a previsão de ressignificação a partir dos movimentos que a sociedade descreve ao longo de seus contextos. Ao se configurar como uma prática de si mesmo e das teorias sobre si, a complexidade se aprofunda na medida em que discute e argumenta sobre sua construção, produzindo sentidos sobre si mesmos, em uma retroalimentação. Assim, o conceito de currículo seria "multifacetado, negociado e renegociado em vários níveis e campos" (GOODSON, 2005, p. 67).

Dada à distinção de que currículo é um conceito construído historicamente, pode ser útil resgatar brevemente sua história para que compreendamos essa complexidade e a construção do artefato no âmbito educacional.

\section{CONSTRUÇÃO HISTÓRICA DE UM CONCEITO}

A origem da utilização educacional do termo currículo data de fins do século XVI e início de século XVII, momento em que ocorreram diversas modificações político-sociais conduzindo a reformas pedagógicas e a uma nova concepção de ensino e aprendizagem, que incluía um controle maior da organização dos estudantes e dos conteúdos e métodos pedagógicos (HAMILTON, 1992). Derivado da palavra latina currere que se reporta a uma pista de corrida, a um caminho ou percurso a seguir, a incorporação do termo ao meio educacional

parece ter confirmado a ideia [...] de que diferentes elementos de um curso deveriam ser tratados como peça única, [como uma] entidade educacional que exibe tanto globalidade estrutural quanto completude sequencial [indicando que] o currículo deveria não apenas ser 'seguido' deveria ser também 'completado' (HAMILTON, 1992, p. 43, destaque do autor).

Contudo, é preciso cautela. Pacheco (2005, 2005, p. 33) nos alerta sobre as errôneas definições que podem tender a "conceituar currículo como um plano, totalmente previsto ou prescritivo", e que devemos levar em conta que para além de uma linha fixa a seguir, um currículo é

organizado em função de propósitos educativos e de saberes e atitudes, crenças e valores que os intervenientes curriculares trazem consigo e que realizam no contexto das experiências e dos processos de aprendizagem formais ou informais (IDEM, ibidem).

Mantendo uma ideia de sequência, de etapas a cumprir, de todo da formação do estudante, a emergência do currículo - enquanto conceito e prática - impõe maior controle tanto para o ensino quanto para a aprendizagem, e "tende a legitimar certos grupos e tendências em desfavor de outros" (NÓVOA, 1997, p. 14), a partir da determinação de conteúdos a serem incorporados no processo de escolarização das massas, conteúdos esses que têm de ser previamente determinados e organizados com finalidades 
específicas. Todavia, não apenas impõe controle sobre conteúdos, também estabelecerá controle sobre os processos de aprendizagem, sobre as conformações estruturais e espaciais, e mesmo sobre o corpo dos estudantes, que a partir de então passam a se portar diante da educação de forma mais restrita e contida.

\section{CONSTRUÇÃO, HISTORICIDADE E PODER DO ARTEFATO}

Com a dimensão de controle e organização do processo educacional, no início do século XX iniciamse os estudos sobre o que ensinar sendo designado como visão tradicional do currículo (LOPES; MACEDO, 2011), compreendendo-o como "um conjunto de fatos, de conhecimentos, de informações, selecionados do estoque cultural mais amplo da sociedade, para serem transmitidos às crianças e aos jovens nas escolas" (SILVA, 2006, p. 13).

Assim, nesta visão, essencialmente o currículo consistia em escolher alguns dados que seriam repassados aos escolares como conteúdos de aprendizagem. Não se entrevê que a fonte de coleta de dados possa ser modificada, tampouco que essa fonte pudesse não ser representativa do conhecimento social mais diverso. O currículo era estabelecido e transmitido, aproximando-o da compreensão de ser um rol de conteúdos organizados em horários específicos, com determinados métodos e avaliações que fazem com que esses conteúdos sejam cumpridos e ensinados de forma eficiente. De modo geral, era um plano previamente estabelecido, onde se listavam etapas a serem cumpridas para atingir a máxima eficiência e produtividade, imprimindo ao cotidiano da escolarização de massa crescente as concepções de organização da emergente sociedade industrial do início do século XX.

Na década de 1960, as convulsões sociais ${ }^{4}$ induzem ao processo de reflexão em todas as áreas, e na educação a visão sobre o currículo é deslocada: de um documento técnico-prescritivo, preocupado com a eficiência do ensino através do estabelecimento de parâmetros a serem seguidos, para uma preocupação e questionamento sobre o quê o motiva, como ele é produzido, e quais as intenções que levaram àquela expressão curricular, ressaltando-se "tanto o caráter histórico (variável, mutável) quanto o caráter social (construído) do conhecimento escolar" (SILVA, 2006, p. 13).

Com enraizamento nas relações do capital e na dinâmica das classes sociais, a emergente teoria crítica visualiza o currículo como uma manutenção da reprodução das diferenças culturais e sociais, estabelecendo formas de escolarização para as elites e para as classes trabalhadoras. Aqui "aprende-se na escola não apenas o que é preciso saber para entrar no mundo produtivo, mas códigos a partir dos quais se deve agir na sociedade" (LOPES; MACEDO, 2011, p. 26-27), distinguindo a escola como um aparelho ideológico do Estado 5 , preocupado em manter as diferenças e restringir o pensamento crítico e a emancipação das classes trabalhadoras.

Importante citar que é sob esta discussão que o conceito de currículo oculto se firma, como forma de denominar todo o aprendizado do educando que extrapola os conteúdos escolares, mas que o prepara para a vida em sociedade, ampliando a compreensão do conceito de currículo ao incluir elementos não palpáveis e prescritos, mas, que circulam tanto no espaço-tempo escolar quanto nas origens das

\footnotetext{
${ }^{4}$ Citamos apenas alguns fatos acontecidos ao longo da década de 1960 que contribuíram com as mudanças: polarização do mundo em capitalismo/socialismo e expansão das duas vertentes (ruptura das relações diplomáticas dos Estados Unidos da América com Cuba e seu abrigo pela URSS; envio pela União Soviética do primeiro homem ao espaço; construção do muro de Berlim, Guerra do Vietnã e da Coréia, revolução Cultural da China); avanço das tecnologias de comunicação (transmissão via satélite); movimentos sociais e manifestações públicas de combate à segregação e ao racismo (campanha não violenta do pastor norte americano Martin Luther King, ações armadas de Malcolm X; greves e manifestações estudantis; grandes marchas reivindicatórias da sociedade).

${ }^{5}$ Para Louis Althusser a escola é o principal aparelho ideológico do estado, uma vez que é ela quem forma as forças produtivas para o mercado de trabalho, mantendo e estimulando as relações capitalistas de empregadoempregador e a lógica de produção do capital (ALTHUSSER, 1985).
} 
intenções curriculares e marcam o processo de formação do educando.

Com o reconhecido caráter social e histórico do currículo, outras reflexões se agregam à discussão, não como forma de superação da teoria crítica estritamente, mas na tentativa de, ao se combinar e reanalisar os componentes, se chegar a graus de compreensão distintos, estabelecendo a corrente de pensamento pós-crítica (SILVA, 2009).

Nesta reflexão, a dimensão de aparelho ideológico é revisitada e o currículo oculto é considerado parte do currículo e não algo escondido, que espreita o processo formativo. O currículo aufere uma diversidade de compreensões e manifestações mediadas pelo multiculturalismo, pelas discussões de gênero, raça, sexo, e é percebido como um promotor de identidades. O dimensionamento é de um artefato em constante movimento situado em um território de disputas e lutas por legitimidade se reforça, ganhando, entretanto, a apreensão de que estas lutas não lhe são externas, mas são inerentes, integram o produto, ou seja, "o currículo faz parte da própria luta pela produção do significado, a própria luta pela legitimação” (LOPES; MACEDO, 2011, p. 92).

A dimensão pós-crítica concorda com a dimensão crítica de que o currículo é um espaço de poder e controle, porém, este poder se mostra descentrado em diversas frentes e não apenas configurado em um foco imanente. O poder está presente nos currículos como parte de sua constituição, pois vinculado à dinâmica de conhecimentos nele expresso, em um processo de inter-relação que lhe é intrínseca, pois "o conhecimento não é aquilo que põe em cheque o poder: o conhecimento é parte inerente do poder" (SILVA, 2009, p. 149). Além disso, "todo conhecimento depende da significação e esta, por sua vez, depende de relações de poder" (Idem, ibidem), fazendo com que o artefato se constituía e mostre nas disputas pelos espaços e tempos de conhecimentos. Nada obstante, ele não é o resultado estrito desta disputa, não é o 'louro do vencedor' e sim o processo, o percurso que descreveram os grupos e indivíduos na organização curricular no sentido de chegar a consensos ou dissensos sobre o processo. O produto final é um produto cultural, que inclui

[...] planos e propostas [...], o que de fato acontece nas salas de aula [...], bem como as regras e as normas não explicitadas que governam as relações que se estabelecem nas salas de aula [...] no currículo desenvolvem-se representações, codificadas de forma complexa nos documentos, a partir de interesses, disputas e alianças, e decodificadas nas escolas, também de modo complexo, pelos indivíduos presentes. Sugere-se ainda a visão do currículo como um campo de lutas e conflitos em torno de símbolos e significados (MOREIRA, 2011, p. 15).

Portanto, a concepção que se propõe de currículo abrange a normatização, a regra, o documento físico indicador das práticas, considerado aqui não apenas os planos de aula, planos de curso, projetos pedagógicos, mas também as regulamentações e as legislações. Todavia, acrescentem-se também as relações estabelecidas em vários âmbitos, envolvendo os documentos, os grupos de protagonistas, as discussões, as disputas, os territórios, os espaços e mediações de poderes explícitos e implícitos, a busca de significados e significâncias que constrói todo um objeto que não pode ser entendido de forma isolada, mas a partir desta complexidade que lhe é inerente e materializada na trama desse tecido.

Importa notar que o currículo escolar é um artefato social, cultural, histórico inventado na transição dos séculos XVI e XVII e chega até a contemporaneidade trazendo para o espaço-tempo escolar as questões de sua concepção e organização que se mostram essenciais na compreensão do produto final, contudo, exatamente pela característica histórica, este produto pode ser considerado final, mas não finalizado, pois mantém os fluxos de mudança em cada fase de análise e busca de sentidos nas diversas etapas de sua prática.

Ou seja, este produto final que nos chega "não foi estabelecido, de uma vez por todas, em algum ponto privilegiado do passado. Ele está em constante fluxo e transformação [e não é] resultado de um processo evolutivo" (SILVA, 2011, p. 7), mas resultado de um processo que visa ao constante revisar e aperfeiçoar do produto, sempre levando em consideração a valoração e expectativas de cada grupamento proponente do artefato, que exercem poder pontual sobre o produto final, moldando-o e 
conformando-o.

Compreender o currículo a partir de sua historicidade não é alinhar os fatos e os eventos que se sucederam para reconstruir uma narrativa linear que se corporifica em um produto final oficial, e sim superar essas narrativas compondo e contrapondo às contingências dos espaços-tempos de suas propagações, compreendendo-as a partir das continuidades, rupturas e negociações e não como uma evolução progressiva dos ideais e concepções. É buscar entender que o que está posto no currículo foi sujeitado e é sujeito a mudanças, flutuações, condicionamentos, conflitos, supressões, e que estes imbricamentos não apenas configuram o currículo, mas deixam suas marcas, percebendo "como as categorias do passado são trazidas para o presente à medida que certos padrões disciplinadores são incorporados através da organização dos conhecimentos" (POPKEWITZ, 1999, p. 194).

Retomando a metáfora de Veiga Neto (2011), a moldura que envolve a obra é parte da obra e tem de ser pensada em conjunto. $O$ estudo do currículo permite entrever como

as influências e interesses ativos intervêm [em sua forma final], promove[m] o nosso conhecimento relativamente aos valores e objetos representados na educação, [além de marcar alguns] parâmetros para a realização e negociações interativas na sala de aula e na escola (GOODSON, 1997, p. 20-21).

O currículo não é algo dado, é um produto sempre em modificação "de um longo e contínuo conflito" (GOODSON, 2005, p. 110), que expressa valores e sujeições, pois não é

um elemento inocente e neutro de transmissão desinteressada do conhecimento social. O currículo está implicado em relações de poder, o currículo transmite visões sociais particulares e interessadas, o currículo produz identidades individuais e sociais particulares. (MOREIRA; SILVA, 2011, p. 14).

Logo, as concepções e disputas que se entretecem no currículo estão profundamente impregnadas de relações de poder, uma vez que estas disputas selecionam ou refinam concepções específicas dos grupos mais hegemônicos em determinado recorte temporal, fazendo com que estas concepções sejam as que cheguem não apenas aos educandos, mas a todos os envolvidos no processo de realização do instrumento curricular.

Considerando que um currículo é um terreno de disputas e relações de poder, os conhecimentos a ele associados acabam por configurar também essas disputas, são construções sócio-políticas cujos "atores envolvidos empregam uma gama de recursos ideológicos e materiais para levarem a cabo as suas missões, individuais e coletivas" (GOODSON, 1997, p. 27).

Assim, não se pode acreditar que as inserções e exclusões curriculares sejam um processo neutro e inocente, onde "acadêmicos, cientistas e educadores desinteressados e imparciais determinam por dedução lógica e filosófica, aquilo que convém ensinar às crianças, jovens e adultos" (SILVA, 2005, p. 8). Ao contrário, é preciso compreender que o currículo é um território de contestações, não um processo

no qual convivem lado a lado com fatores lógicos, epistemológicos, intelectuais, determinantes sociais menos "nobres" e menos "formais", tais como interesses rituais, conflitos simbólicos e culturais, necessidades de legitimação e de controle, propósitos de dominação dirigidos por fatores ligados à classe, à raça, ao gênero (SILVA, 2005, p. 8, destaque do autor).

Como indica Forquin (1992), o currículo é organizado em torno dos conteúdos que contam mais, que sejam mais importantes na visão dos seus propositores, ou seja, aqueles conteúdos cujos defensores entrem na disputa com argumentos mais contundentes e agreguem maior legitimidade às falas, por isso os currículos expressam um processo de construção sócio histórico, mediado pela seleção baseada no que importa mais para os grupos dominantes naquele recorte temporal, e refletem o que se intenta para o estudante sujeito a ele, o que se espera alcançar como marca de identidade, identidade esta obtida não 
apenas na submissão ao currículo, mas também na própria constituição dos grupos curriculares que travarão as batalhas.

É importante sinalizar que, ainda que tenhamos habitualmente o estabelecimento da relação entre os termos conteúdos e matéria, não se indica aqui que estas seleções de conteúdos restrinjam-se a 'o que ensinar', mas a todo o constructo que envolve o currículo. Veiga-Neto (2013) nos auxilia e amplia ao indicar o currículo como um artefato escolar que extrapola a organização dos conteúdos, saberes e procedimentos de ensino, que funcionaria

como um eficiente e sutil promotor de determinadas disposições ou esquemas mentais e corporais que se manifestam nos modos pelos quais entendemos o mundo, nos relacionamos com os outros e, talvez principalmente, compreendemos a nós mesmos (VEIGA-NETO, 2013, p. 162).

Nesse sentido, o currículo ganha papel central na construção do sujeito, pois

Articula o que pensamos e como pensamos (aquilo que fazemos) com o que fazemos e como fazemos (aquilo que pensamos). É na combinação entre o pensar o que se faz e o fazer o que se pensa que nos compreendemos como sujeitos e, a partir daí, nos identificamos (mais ou menos) com os outros (VEIGANETO, 2013, p. 163, destaques do autor).

A identidade que o currículo ajuda a construir é uma identidade composta de esquemas mentais, mas também de relações corporais. A sujeição do estudante ao currículo impõe as contingências físicas e mentais a este estudante que se materializam em paredes, carteiras, livros, mas também em silêncios e inatividade. O oposto também é possível: o currículo pode não sujeitar o estudante, mas estimular à inquietude mental e física. De qualquer forma, como sintetiza Silva (2005, p. 10) "o currículo está construído para ter efeitos (e tem efeitos) sobre pessoas [...] diferentes currículos produzem diferentes pessoas".

Reconhecer currículos como construções histórico-sociais implica reconhecer que há uma materialidade $^{6}$ e uma subjetividade em suas manifestações inerentes ao próprio artefato. É possível observar esta materialidade através, por exemplo, dos programas de ensino, das legislações e regulamentações, assim como a subjetividade se dá nos entremeios da produção destes programas, destas legislações, destas regulamentações, através das disputas e acordos que os grupamentos curriculares encetam em sua gestação e desenrolar. Todavia é preciso compreender que a materialidade e subjetividade se apresentam não apenas em registros escritos, mas em todos os registros do artefato no seu tempo, ao que nos leva à imprescindibilidade de compreensão dos espaços que o currículo ocupa, buscando compreender o quê estes espaços representam em sua constituição.

\section{ESPAÇO, LUGAR, TERRITÓRIO E PRÁTICAS}

O termo espaço é uma categoria de análise que se relaciona à manifestação física, palpável, assim, tendemos a entender que o espaço de um currículo seria a instituição educacional que o colocará em prática. Contudo, esta simplificação não dá conta de compreender a dimensão que o espaço adquire no desenrolar de um currículo, pois ele está muito vinculado às potencialidades que o instrumento pode alcançar em sua prática, em seu cotidiano. Por isso, divisar o espaço como um cenário onde será aplicado um currículo é perder a potencialidade deste espaço como um espaço educador, pois ele é planejado, analisado, pensado para receber determinado currículo e traz nesse planejamento aspirações ideológicas e seleções conceituais que vão concorrer para a execução curricular.

O edifício escolar, construído ou adaptado para tal, é uma concretização da concepção pedagógica do currículo ao determinar e regular os fluxos e nichos de pessoas e atividades, trazendo explicitada nas paredes, portas, sanitários, decorações, fachadas, e até na relação que estabelece com os outros edifícios

${ }^{6}$ O termo materialidade busca inspiração na categoria materialidade de Roger Chartier (1999), porém aqui é usado de forma mais circunscrita às manifestações palpáveis, concretas, físicas até mesmo, que o currículo possa apresentar. 
de seu entorno, as representações estéticas e culturais, demonstrando visualmente qual o papel e ação de cada protagonista curricular, ou seja,

A arquitetura escolar é também por si mesma um programa, uma espécie de discurso que institui na sua materialidade um sistema de valores, como os de ordem, disciplina e vigilância, marcos para a aprendizagem sensorial e motora de toda uma semiologia que cobre diferentes símbolos estéticos, culturais e também ideológicos (ESCOLANO, 2001, p. 26).

Pensar um espaço curricular é entender como este espaço se comporta em seu potencial educador e regulador das aspirações e pretensões dos currículos, é pensar como as distâncias e as paredes comportam e conformam a ação curricular, mas é também pensar como esta fisicalidade do espaço é apropriada e manipulada pela ação dos indivíduos e grupamentos, pois, se o espaço educa a ação das pessoas neste espaço também, daí a importância de compreendermos a distinção e imbricamentos das categorias espaço e lugar.

Viñao Frago (2001) estabelece uma relação entre espaço e lugar nos meandros da sua construção e ocupação:

A ocupação do espaço, sua utilização, supõe sua constituição como lugar. O "salto qualitativo" que leva do espaço ao lugar é, pois, uma construção. O espaço se projeta ou se imagina; o lugar se constrói. Constrói-se "a partir do fluir da vida" e a partir do espaço como suporte; o espaço, portanto, está sempre disponível e disposto para converter-se em lugar, para ser construído (VIÑAO FRAGO, 2001, p. 61, destaques do autor).

A atribuição de sentidos, a vivência, a significação que se constrói nos espaços extrapola sua fisicalidade, modificando a percepção que se tem destes, ou poderíamos dizer - usando um neologismo que se vai "lugarizando" estes espaços, vai se tornando num lugar, que "passa a ser cada vez mais entendido e vivido como uma projeção, neste assim chamado mundo sensível, de um espaço ideal" (VEIGANETO, 2002b, p. 208).

Cunha (2008) atribui à ação humana a energia transformadora do espaço em lugar, ao nos indicar que o espaço é "sempre potencial, abriga a possibilidade de existência de programas [contudo] não garante a sua efetivação" (p. 184b), a conversão do potencial, do concreto, do físico representado pelo espaço em lugar se dá na atribuição de sentidos, quando "reconhecemos sua legitimidade para localizar ações, expectativas, esperanças, possibilidades [atribuindo] um sentido cultural, subjetivo e muito próprio ao exercício de tal localização" (CUNHA, 2008, p. 184c).

Desse modo, o espaço seria a possibilidade, uma realidade potencial que se objetifica no momento em que ele é ocupado e constituído, estabelecendo-se finalidades e usos a partir das representações que os grupamentos ocupantes têm acerca daquela construção. O lugar é "o espaço preenchido, não desordenadamente, mas a partir dos significados de quem o ocupa" (CUNHA, 2008, p. 185a).

O espaço é um edifício, são paredes e telhados, mas carrega em si a subjetividade, pois, ainda que planejado para abrigar uma ocupação específica, este espaço se tornará concreto em sua ocupação real, ganhando o atributo de objetividade e tornando-se um lugar. É a dimensão do currículo proposto que converte espaços em lugares e lugares novamente em espaços, dando ao edifício e à instituição que ele abriga a dimensão de espaço e de lugar, concomitantes: "a escola é espaço e lugar. Algo físico, material, mas também uma construção cultural” (VIÑAO FRAGO, 2001, p. 77).

Retomando o neologismo, a "lugarização" de um espaço depende da atribuição de sentidos, da legitimidade que os indivíduos e grupamentos lhe imporão a partir de suas próprias perspectivas sobre o currículo que ali se manifesta. Portanto, um espaço até pode ser mais fixado, menos móvel, mas um lugar não, pois, este depende das experiências próprias dos planejadores e dos ocupantes para se concretizar, 
decorrendo daí a necessidade de compreensão ubíqua do espaço e do lugar. Não se trata de delimitar o espaço como a manifestação física e o lugar como a manifestação emocional e/ou ideológica sobre esta fisicalidade, mas de compreender que espaço e lugar estão intrincados, uma vez que os lugares se constituem a partir da apropriação dos espaços e os espaços se concretizam a partir da sua "lugarização", constituindo uma dupla educadora que tem potenciais distintos e complementares.

A relação entre espaço e lugar leva a refletir sobre a ação humana nesta construção. Tornar um espaço um lugar é mediado pelas perspectivas curriculares que se dão, contudo, o currículo é mediado por relações de poder e controle que se manifesta nesta apropriação dos espaços, conformando identidade dos grupos curriculares, importando, assim o território, que traz uma dimensão mais fluida e menos concreta de distribuição do espaço que o lugar, podendo se sobrepor e expandir, o que faz com que o espaço escolar abrigue ambos.

O território se constrói nos limites entre o indivíduo ou grupo e suas pretensões e intenções com determinado espaço-tempo curricular, território é

uma noção subjetiva ou caso se prefira, objetivo-subjetiva - de índole individual ou grupal e de extensão variável. Uma extensão que vai desde os limites físicos do próprio corpo - ou de determinadas partes do mesmo - até o espaço mental dos projetos, ali até onde chega o pensamento que prenuncia a ação e o deslocamento (VIÑAO FRAGO, 2002, p. 63).

Territórios se organizam a partir das disputas travadas nos currículos, onde os grupos curriculares se mostram com maior ou menor prerrogativa de influenciar a ocupação dos espaços. Ao abrigar a "liturgia acadêmica [os espaços ganham] significados e transmitem uma importante quantidade de estímulo, conteúdos e valores" (ESCOLANO, 2001, p. 27), que estão dispostos no currículo institucional, tanto na forma de preceitos e disciplinarização do sujeito escolar, quanto na organização matricial das disciplinas escolares, que "na medida em que cada matéria/disciplina ocupa determinadas células nessa matriz, a divisão epistemológica entre as matérias assume uma materialidade visível" (VEIGA-NETO, 2002b, p. 214), levando-nos a refletir que os territórios são constituídos em decorrência das relações de poder que os grupamentos descrevem ao longo do processo de organização, construção e mudança de um currículo institucional.

Cunha (2008, p. 185b) sintetiza a relação de complementariedade e retroalimentação entre espaçolugar-território, ao sinalizar que "O espaço se transforma em lugar quando os sujeitos que nele transitam Ihe atribuem significados. O lugar se torna território quando se explicitam os valores e dispositivos de poder de quem atribui significado". Assim, partindo de uma fisicalidade potencial que a introdução do currículo impõe, a ação dos protagonistas curriculares nessa fisicalidade a transforma, tornando-a um lugar a partir da série de representações, expectativas, valores, significações. A intencionalidade e as relações de poder e valoração embutidas não se limitam à fisicalidade tornada lugar, e expandem sua zona de influência construindo superposições territoriais.

Os protagonistas no currículo são, portanto, essenciais na sua construção, pois é nos meandros da ação-reação-inação que se configuram as manifestações espaço-temporais do currículo e se constroem os territórios de atuação/influência, que extrapolam a observação física concreta do espaço e interfere na própria forma de construir o currículo enquanto um manifesto destas relações:

O currículo visto como produto acabado, concluído, não pode deixar de revelar as marcas das relações sociais de sua produção. Desde sua gênese como macro texto de política curricular até sua transformação em microtexto de sala de aula, passando por seus diversos avatares intermediários (guias, diretrizes, livros didáticos) vão ficando registrados no currículo os traços das disputas por predomínio cultural, das negociações em torno das representações dos diferentes grupos e das diferentes tradições culturais, das lutas entre, de um lado, saberes oficiais, dominantes e, de outro, saberes subordinados, relegados, desprezados (SILVA, 2006, p. 22). 
As intencionalidades fazem com que o currículo se apresente diferenciado conforme o ponto que se observa e tal qual a dimensão espaço-territorial dele, constituindo um hiato entre a proposição formal e a efetivação destas. Estabelecem-se espaços-tempo do currículo observado entre o que é prescrito e o que é praticado, ou seja, o que está indicado em um documento que traria a determinação da formação - como legislação, regulamentos, projetos pedagógicos e outros - e o que de fato acontece no percurso formativo mediado pelo cotidiano institucional. O currículo vai sendo transformado e transformando, resistindo e sendo moldado, conforme cada momento, cada protagonista, cada espaço-tempo, e pelas relações estabelecidas entre todos estes elementos, constituindo um currículo real praticado que se afasta do prescrito, conservando maior ou menor relação com este?

Portanto, reconhecer que existe uma diferença entre o currículo prescrito e o currículo praticado é reconhecer que as mudanças são inerentes e intrínsecas ao processo, é reconhecer a existência de diferentes grupos, lutas, tradições que mediam estas mudanças, pois o currículo enquanto artefato está submetido à ação humana, "às relações sociais no interior das quais se realizam as práticas de significação" (SILVA, 2006, p. 23), relações estas que não se resumem a simples relações entre indivíduos, mas que se configuram como "relações sociais de poder [que são] ao mesmo tempo, resultado e origem do processo de significação" (IDEM, ibidem).

Goodson (2008) agrupa as situações de mudança que ocorrem nos currículos em três segmentos. As internas, que "operam no ambiente escolar para iniciar e promover a mudança em um arcabouço externo de apoio e de patrocínio"; as externas, reconhecidas como "administradas de cima para baixo como as diretrizes do Currículo Nacional"; e as pessoais, que se referem às "crenças e missões pessoais que indivíduos trazem para o processo de mudança" (GOODSON, 2008, p. 41). O autor sinaliza que estes segmentos podem se interligar ou não para promover as mudanças, que podem ser impulsionadas por um dos segmentos, por dois, ou pela coalização de todos e que, ainda que sejam mais habituais que as mudanças sejam impelidas por um segmento isolado, estas mudanças terão mais força quanto maior a harmonia e integração entre os segmentos.

O estabelecimento do currículo prescrito e do currículo praticado pode ser mais ou menos expressiva, revelar maior ou menor resistência quanto menor ou maior integração, harmonia, representatividade os segmentos propositores do currículo encontrem nas propostas, pois, esta integração faria com que a prescrição se aproximasse das possibilidades, do cotidiano, das expectativas pessoais dos agentes executores, reduzindo a polarização.

\section{PODER E COMUNIDADES CURRICULARES}

No âmbito das mudanças, Lopes (2011) indica duas comunidades curriculares que protagonizam a produção de políticas e desempenham papel preponderante: as comunidades disciplinares e as comunidades epistêmicas.

Uma vez que o currículo marca, de forma contundente, os recursos destinados a cada área disciplinar, os padrões de conduta identitários e as forças dos grupos dominantes, sua construção embasa-se nas preferências e supressões nos campos disciplinares (GOODSON, 1997), mesmo considerando novas formas de organização curricular que superem os limites fixos das disciplinas, mas que acabam partindo delas.

\footnotetext{
${ }^{7}$ Aqui, optamos por utilizar a terminologia de Goodson (2011) designando por currículo prescrito e currículo ativo ou praticado, por similaridade epistemológica e pela simplificação dos termos sem ser simplório. Contudo, há que se considerar que existem outras formas de designar conforme o alinhamento conceitual do autor consultado, como faz Gimeno Sacristán (2000) que reconhece seis níveis: o currículo prescrito (sistemas e políticas curriculares); o currículo apresentado aos professores (meios que traduzem o currículo para o professor, a exemplo dos livros didáticos); o currículo moldado pelos professores (planejamento e planificação do professor sobre o currículo); o currículo em ação (a prática do professor em aula); o currículo realizado (os efeitos da prática); o currículo avaliado (avaliação da eficiência e efetividade do currículo).
} 
É preciso entender, então, que as disciplinas "não são nem uma vulgarização nem uma adaptação das ciências de referência, mas um produto específico da escola, que põe em evidência o caráter criativo do sistema escolar" (JULIÁ, 2001, p. 33). De forma complementar, podemos supor de uma disciplina construída no âmbito escolar mediada pelos processos culturais que se impõem a partir dos grupos dominantes, e que fincará suas determinações identitárias tanto mais fortes quanto forem os grupos que as propõem.

Originalmente, o significado do termo disciplina era vinculado ao verbo 'disciplinar', então, atrelado aos padrões de conduta e organização da escola e do escolar, porém, ele passa a ser utilizado com o sentido de grupo de conteúdos de um currículo ao final do século XIX, passagem para o século XX (CHERVEL, 1990). Apesar do sentido atual, mantém-se a disponibilidade do caráter disciplinador, regrador e normativo que se vincula ao verbo original, podendo este ser resgatado a qualquer momento. Logo, uma disciplina no âmbito educacional também poderia ser entendida como "um modo de disciplinar o espírito, quer dizer de lhe dar os métodos e as regras para abordar os diferentes domínios do pensamento, do conhecimento, da arte" (IDEM, p. 180).

As disciplinas devem ser compreendidas como parte de um todo e não como entidades isoladas, singulares e alheias às influências extrínsecas e intrínsecas ao seu processo de surgimento, consolidação e modificação. Neste processo, tem importância crucial os indivíduos ou grupamentos representativos de uma disciplina, ou seja, sua comunidade.

Goodson indica que as comunidades disciplinares não são grupos homogêneos, formados por indivíduos de ideias, propostas e valores uniformes convergentes. Ao contrário, estas estão em constante ebulição e incluem “uma gama variável de 'missões' ou 'tradições' distintas representadas por indivíduos, grupos, segmentos ou facções" (GOODSON, 1997, p. 44). As tradições disciplinares constituem o núcleo duro que conduz professores para seu campo, os conforma e os organiza.

As disciplinas são, então, relacionadas e atribuídas a grupos de profissionais que, não apenas se identificam como pertencentes a uma comunidade disciplinar que tem tradições e se ajunta ao redor de sua especialidade disciplinar, mas que ergue barreiras impedindo o livre fluxo com outros profissionais, identificados como pertencentes à outra disciplina, com especialidade, conteúdo e tradições particulares e, portanto, distintas, o que o caracteriza como não pertencente àquela comunidade.

Estas comunidades de especialistas apesar de se reconhecerem como partícipes de uma tradição disciplinar que os levou a se ajuntarem são representantes de interesses e valores distintos, formando grupos dentro da comunidade, o que leva a disciplina a se dispor sobre frouxas coesões historicamente pontuais, já que cada um dos grupos que compõem a comunidade persegue seus próprios objetivos de formas diferentes.

Apesar dos embates internos às disciplinas, que pode levar a uma alternância de poder elevando alguns grupos disciplinares e suas propostas em detrimento de outros, a disciplina ainda tem um longo caminho no sentido de seu estabelecimento e concretização.

A construção de uma retórica bem sucedia para a disciplina pode dar primazia aos interesses materiais, mas, uma vez estabelecida com êxito, a disciplina tem de ser negociada e concretizada em uma série de níveis. A disciplina pode ser pré-activa ao nível das diretrizes, dos manuais escolares ou dos planos de estudo, mas negociada interativamente em níveis subsequentes: o grupo disciplinar, a subcultura da disciplina, a micropolítica diária da disciplina na escola e o habitus da disciplina, e as rotinas diárias da sala de aula por parte do professor da disciplina (GOODSON, 1997, p. 51, destaques do autor).

Observa-se, assim, que estes grupos associados sob a égide de uma disciplina mantêm-se em conflitos de interesses, onde a cada momento histórico poderia se observar um deles emergindo e dominando a disciplina, de forma que identificaríamos estas variações ao longo do tempo de existência de uma disciplina. Esta competição pode ser por ideias e espaço, mas pode ser também por financiamentos. De todas as formas, o prestígio social sempre está em jogo. Por isso, a análise do excluído 
pode ser tão rica quanto à do incluído, pois estes embates dos grupos disciplinares, sua ascensão e queda, podem ser delineados nas inclusões e nas exclusões.

De qualquer forma, qualquer que seja o grupo disciplinar dominante, a política vigente, as transformações socioculturais na qual estiver imersa,

[...] a missão do grupo disciplinar é a de promover a disciplina conquistando os grupos legítimos com vista a obtenção de apoio ideológico e de recursos. Para cumprir esta missão, a definição e retórica da disciplina são, num sentido muito real, um manifesto ou slogan político, porque o fundamento lógico de uma versão específica da disciplina é, neste sentido, uma conveniência política. As disciplinas escolares bem sucedidas devem aparecer como essências incontestáveis e monolíticas (devem seguir como destilações por excelência de uma forma específica, adotando um ponto de vista filosófico). A disciplina tornase um monólito mitificado que existe independentemente da sua realização específica como prática estruturada ou institucionalizada (GOODSON, 1997, p. 51).

Uma disciplina deve parecer uma única estrutura coesa e coerente, de aspirações e necessidades uníssonas, construindo seus mitos e tradições a partir das quais a comunidade defende a disciplina e se identifica com ela. Contudo, por trás da aparente estabilidade e solidez de uma disciplina, da identificação de seus membros através das comunidades de especialistas disciplinares, mantém-se variados grupos desta comunidade em constante conflito para fazer valer seus próprios preceitos e que se mantém unidos até um limite.

As constantes pressões externas e internas, as disputas sucessivas e recorrentes, podem levar este conglomerado aparentemente sólido a ruir e se metamorfosear, ou mesmo deixar de existir enquanto entidade única e isolada e desaparecer ou ser integrada a novos aglomerados, compondo novas disciplinas. É com esse panorama interno das comunidades disciplinares que Goodson (2001, p. 101) propõe que compreendamos que "as disciplinas não são entidades monolíticas, mas, antes, amálgamas flutuantes de subgrupos e de tradições que, através da contestação e do compromisso, influenciam o rumo das mudanças".

Esta percepção das comunidades disciplinares tem de ser observada sob a ótica de compreensão do currículo como artefato sócio-histórico-cultural, o que as subjuga às contingências políticas que compõem/superpõem/impõem o espaço-tempo curricular, uma vez que o currículo está "longe de ser um produto tecnicamente racional, que resume imparcialmente o conhecimento tal como ele existe num dado momento histórico [mas] pode ser visto como veículo e portador de prioridades sociais" (GOODSON, 1997, p. 79). Deste modo, prescinde-se da ideia de que os governos instituídos, democráticos ou não, tenham total preponderância e controle sobre as políticas de organização e reforma curricular, uma vez que a construção do instrumento curricular traria em si mesma as discussões de uma parcela da sociedade diretamente vinculada a esta produção, assim como as influências de todo o constructo cultural que o grupo diretamente envolvido traria para a mesa de discussões. O mesmo acontecendo com as comunidades disciplinares que estariam mais centradas na defesa de seus conhecimentos e tradições específicas.

Reforça-se esta concepção ao alinharmos a compreensão de política como uma

reunião de práticas, discursos e instituições que buscam estabelecer certa ordem e organizar a coexistência humana [e também] domesticar hostilidades e tentar desarmar o antagonismo em potencial que existe nas relações humanas (MOUFFE, 2001, p. 417-418).

E cujos processos são "parte de uma vivência social sempre simbolicamente mediada" (LOPES, 2011, p. 21), o que nos leva a pensar em uma coletividade propositora. Mesmo que esta coletividade seja 
flutuante, com maior ou menor expressividade, ela coexiste no exato momento que o indivíduo propositor é um ser social e cultural, e, portanto mediado por estas dimensões de coletividade humana.

Neste sentido, é possível pensar na organização de grupos de indivíduos, oriundos de posições e situações diversas - ou não, variando com a condição - que se envolveriam na proposição de políticas curriculares, derivando, assim, uma comunidade epistêmica:

As comunidades epistêmicas se constituem como rede de profissionais com competência reconhecida, reivindicando autoridade em função do conhecimento que possuem ou supostamente tem. Compartilham crenças e valores derivados de analises que são realizadas com finalidade de apontar problemas e sugerir soluções calcadas em critérios e procedimentos definidos por elas (TORRES; DIAS, 2011, p. 207).

Uma comunidade epistêmica pode ser entendida como um grupamento de profissionais que teriam como objetivo analisar e propor soluções para determinada área de atuação/educação que não necessariamente estejam em uma mesma área de inserção social. Estes profissionais podem se originar de segmentos e facções sociais distintas, porém, trazem o reconhecimento de seus pares como representantes legítimos, pois o atributo de representatividade baseia-se no conhecimento, que podem ou não possuir de fato, mas que é reconhecido por seus pares como existente. Ou seja, uma comunidade epistêmica é organizada em torno da percepção que se tem de que aqueles membros são a melhor escolha, já que seriam os maiores detentores de conhecimento, do poder do conhecimento específico, legitimando não apenas suas trajetórias anteriores até chegarem à composição da comunidade, mas também suas crenças e valores pessoais como representativos da coletividade. Como nos indicam Torres e Dias (2011, p. 208) "ter um conhecimento especializado acerca de determinados assuntos é possuir um papel relevante no processo de produção das políticas; tende a construir uma liderança na arena de luta pela significação das políticas".

Esta liderança não é vitalícia, uma vez que o atributo de conhecimento especializado pode ser superado pela velocidade de obsolescência dos saberes da contemporaneidade, o que confere às comunidades epistêmicas a característica de variação contínua de seus membros, que são substituídos de acordo com o surgimento de indivíduos com reconhecimento maior. Some-se a isso, que as comunidades epistêmicas possuem o atributo da heterogeneidade de saberes, pois diversos especialistas legítimos, oriundos de diversos segmentos e áreas da sociedade e da ciência, são colocados em patamar de igualdade para discutir e fazer prevalecer suas próprias concepções, criando um território de contestação.

Tal a comunidade disciplinar, as comunidades epistêmicas estão "inscritas numa arena de disputas e negociações constantes, atravessadas por relações de saber-poder, a fim de conferir significados para as políticas" (TORRES; DIAS, 2011, p. 211). Ao não apresentarem uma identidade dada como condição sine qua non de constituição, mas que é construída de acordo com a necessidade de discussão e negociação de determinada inserção política, sendo desconstruída a cada política que carece de negociação, "seus discursos estão inseridos numa formação discursiva ampla, marcada pela inconstância, ambivalência e multiplicidade de atores e demandas" (Idem, ibidem), refletindo os territórios contestados que constituem o produto final curricular.

Assim, é preciso considerar que as disputas no território curricular são reais e podem ser acompanhadas dentro das comunidades a ele atreladas. Mais duradouras, as comunidades disciplinares defendem seus espaços dentro deste currículo, baseado na força de suas tradições e legitimidade dos saberes disciplinares. Menos duradouras, as comunidades epistêmicas defendem seus espaços a partir da influência nas proposições das políticas curriculares. Ambas têm como objetivo ampliar sua zona de influência e determinação no espaço curricular. Ambas sofrem com as disputas internas e têm sempre de entrar em processos de negociações com seus membros.

A comunidade disciplinar agrega membros a partir das suas tradições, o que lhe confere uma força específica, sedimentada na crença dos integrantes em comporem-na, mas a subjuga à multiplicidade de 
tradições inerentes, constituindo subgrupos conflituosos em seu interior. A comunidade epistêmica agrega membros a partir da necessidade de influenciar as políticas curriculares e conta com a legitimidade do saber reconhecido dos seus integrantes em suas comunidades disciplinares, o que a subjuga à demanda para aceitação da reforma e à obsolescência de saberes.

\section{CONSIDERAÇÕES FINAIS}

As relações de poder e valoração que agem sobre o percurso de construção e os processos de seleções curriculares estão implícitas no currículo prescrito, contudo, elas não necessariamente se explicitarão no currículo praticado tal qual, podendo levar à releitura e reanálise constantes, criando outro produto que mantém relação íntima e sequencial com o primeiro, pois, ainda que mudanças sejam permitidas, a retórica prescritiva se mantém, dando a coesão necessária para que o artefato curricular seja manifestado.

Portanto, currículos não são seleções ingênuas tampouco manifestações despretensiosas. Eles trazem em seu texto, em sua prescrição, as relações de poder e controle sobre a formação que os protagonistas propositores esperam e que permearam o percurso de sua construção como um artefato representativo de um determinado momento/movimento sócio-histórico-cultural. A partir deste documento de seleções imbrincadas, há a ação dos novos protagonistas, os executores agem sobre esta prescrição e sua prática é também permeada por relações de poder e controle que alterarão o produto observado em sua prática. Há, porém, limite nesta reelaboração, determinada já em sua origem, já em sua prescrição, onde se mantém os fundamentos da retórica propositora e se permite o entremeado de ações cotidianas.

Currículos estão direta e imediatamente mediados pelo processo social que os produz, estão repletos de seleções de conhecimentos considerados válidos para o recorte que o produziu, e carregam em si o potencial aculturador a estas seleções, porque fortemente permeado dos rituais e operações de poder sociocultural.

\section{REFERÊNCIAS}

ALTHUSSER, Louis. Aparelhos ideológicos de estado: notas sobre os aparelhos ideológicos de estado. 3. ed. Rio de Janeiro: Graal, 1985.

APPLE, Michael W. Política cultural e educação. São Paulo: Cortez, 2000.

APPLE, Michael W. Repensando ideologia e currículo. In: MOREIRA, Antonio Flávio Barbosa; SILVA, Tomáz Tadeu da. Currículo, cultura e sociedade. 12. ed. São Paulo: Cortez, 2011. p.49-69.

CHARTIER, Roger. O mundo como representação. In: CHARTIER, Roger. À beira da falésia: a história entre certezas e inquietude. Porto Alegre: Editora UFRGS, 2002. p. 61-79.

CHERVEL, André. História das disciplinas escolares: reflexões sobre um campo de pesquisa. Teoria \& Educação. v. 2, p. 177-229, 1990.

COSTA, Marisa Vorraber. Currículo e política cultural. In: COSTA, Marisa Vorraber (org). 0 currículo nos limiares do contemporâneo. 3. ed. Rio de Janeiro: DP\&A, 2001. p.37-68.

CUNHA, Maria Isabel da. Os conceitos de espaço, lugar e território nos processos analíticos da formação dos docentes universitários. Educação Unisinos. v. 12, n. 3, p. 182-186, 2008.

DIAS, Rosanne Evangelista; LÓPEZ, Silvia Braña. Conhecimento, interesse e poder na produção de políticas curriculares. Currículo sem Fronteiras. v. 6, n. 2, p. 53-66. 2006.

ESCOLANO, Agustín. Arquitetura como programa: espaço-escola e currículo. In: VIÑAO FRAGO, Antonio; ESCOLANO, Agustín. Currículo, espaço e subjetividade: a arquitetura como programa. 2. ed. Rio de Janeiro: DP\&A, 2001. p. 21-57.

FORQUIN, Jean-Claude. Saberes escolares, imperativos didáticos e dinâmicas sociais. Teoria \& Educação. 
v. 5, p. 28-49, 1992.

GIMENO SACRISTÁN. José. O currículo: uma reflexão sobre a prática. 3. ed. Porto Alegre: Artmed, 2000. GOODSON, Ivor F. A construção social do currículo. Lisboa: Educa, 1997. (Coleção Educa Currículo) GOODSON, Ivor F. As políticas de currículo e de escolarização: abordagens históricas. Petrópolis: Vozes, 2008.

GOODSON, Ivor F. Currículo: teoria e história. 11 ed. Petrópolis: Vozes, 2011.

GOODSON, Ivor F. O currículo em mudança: estudos na construção social do currículo. Porto: Porto Editora, 2001.

HAMILTON, David. Sobre as origens dos termos classe e curriculum. Teoria \& Educação. v. 6, p. 33-52, 1992.

HOBSBAWM, Eric. Introdução: a invenção das tradições. In: HOBSBAWM, Eric; RANGER, Terence (orgs). A invenção das tradições. 6. ed. São Paulo: Paz e Terra, 2008. p. 9-24.

JULIÁ, Dominique. Disciplinas escolares: objetivos, ensino, apropriação. In: LOPES, Alice Casimiro; MACEDO, Elizabeth (orgs). Disciplinas e integração curricular: história e políticas. Rio de Janeiro: DP\&A, 2002. p.37-71.

LIMA, Idelsuite de Sousa. A interrelação curricular. In: PEREIRA, Maria Zuleide Costa; LIMA, Idelsuite de Sousa (orgs). Currículo e políticas educacionais em debate. Campinas: Alínea, 2012. p. 151-162.

LOPES, Alice Casimiro. Políticas de currículo: questões teórico-metodológicas. In: LOPES, Alice Casimiro; DIAS, Rosanne Evangelista; ABREU, Rozana Gomes de (orgs). Discursos nas políticas de currículo. Rio de Janeiro: Quartet, Faperj, 2011. p. 19-47.

LOPES, Alice Casimiro. Políticas de integração curricular. Rio de Janeiro: EDUERJ, 2008.

LOPES, Alice Casimiro; MACEDO, Elizabeth. Teorias de currículo. São Paulo: Cortez, 2011.

LOPES, Jader Janer Moreira. Reminiscências da paisagem: vozes, discursos e materiais na configuração das escolas na produção do espaço brasileiro. In: LOPES, Jader Janer Moreira; CLARETO, Sonia Maria (orgs). Espaço e educação: travessias e atravessamentos. Araraquara: Junqueira Marin, 2007. p. 73-98.

MACEDO, Roberto Sidnei. Currículo: campo, conceito e pesquisa. 2. ed. Petrópolis: Vozes, 2008.

MOREIRA, Antonio Flávio Barbosa. Currículo, utopia e pós-modernidade. In: MOREIRA, Antonio Flávio Barbosa (org). Currículo: questões atuais. 18. ed. Campinas: Papirus, 2011. p. 9-27.

MOREIRA, Antonio Flávio Barbosa; SILVA, Tomáz Tadeu. Sociologia e teoria crítica do currículo: uma introdução. In: MOREIRA, Antonio Flávio Barbosa; SILVA, Tomáz Tadeu da. Currículo, cultura e sociedade. 12. ed. São Paulo: Cortez, 2011. p. 13-47.

POPKEWITZ, Thomas S. História do currículo, regulação social e poder. In: SILVA, Tomáz Tadeu da (org). O sujeito da educação: estudos foucaultianos. 3. ed. Petrópolis: Vozes, 1999 (Coleção Ciências Sociais da Educação). p. 173-209.

POPKEWITZ, Thomaz. Reforma educacional: uma política sociológica - poder e conhecimento. Porto Alegre: Artes Médicas, 1997. p. 148-155.

SILVA, Tomaz Tadeu da. Apresentação. In: GOODSON, Ivor F. Currículo: teoria e história. 11 ed. Petrópolis: Vozes, 2011. p. 7-13.

SILVA, Tomaz Tadeu da. Currículo como fetiche: a poética e a política do texto curricular. Belo Horizonte: Autêntica, 2006.

SILVA, Tomaz Tadeu da. Documentos de identidade: uma introdução às teorias do currículo. 3. ed. Belo Horizonte: Autêntica, 2009.

SILVA, Tomaz Tadeu da. Os novos mapas culturais e o lugar do currículo numa paisagem pós-moderna. 
In: SILVA, Tomaz Tadeu da; MOREIRA, Antonio Flávio Barbosa. Territórios contestados: o currículo e os novos mapas políticos e culturais. 6. ed. Petrópolis: Vozes, 2004. p. 184-202.

SILVA, Tomáz Tadeu. Currículo e identidade social: territórios contestados. In: SILVA, Tomáz Tadeu (org). Alienígenas na sala de aula. 6. ed. Petrópolis: Vozes, 1995.

SOUZA, Ruy Guilherme Silveira de. Estratégia de mobilização para as transformações curriculares. In: MARINS, João José Neves; REGO, Sérgio (orgs). Educação médica: gestão, cuidado, avaliação. São Paulo: Hucitec, Rio de Janeiro: ABEM, 2011. p. 67-82.

TAVANO, Patricia Teixeira. Onde a morte se compraz em auxiliar a vida: A trajetória da disciplina de Anatomia Humana no currículo médico da primeira Faculdade oficial de Medicina de São Paulo - o período de Renato Locchi (1937-1955). 2011. 287f. Dissertação (Mestrado em Educação) - Faculdade de Educação, Universidade de São Paulo, São Paulo.

TORRES, Wagner Nóbrega; DIAS, Rosanne Evangelista. Comunidades epistêmicas nas políticas de currículo em EJA. In: LOPES, Alice Casimiro; DIAS, Rosanne Evangelista; ABREU, Rozana Gomes de (orgs). Discursos nas políticas de currículo. Rio de Janeiro: Quartet, Faperj, 2011. p. 205-223.

VEIGA NETO, Alfredo. Currículo e história: uma conexão radical. In: COSTA, Marisa Vorraber (org). 0 currículo nos limiares do contemporâneo. 3. ed. Rio de Janeiro: DP\&A, 2001. p. 93-104.

VEIGA-NETO, Alfredo. Cultura e currículo. Contrapontos. v. 2, n. 4, p. 43-51, $2002 a$.

VEIGA-NETO, Alfredo. Currículo e interdisciplinaridade. In: MOREIRA, Antonio Flávio Barbosa (org). Currículo: questões atuais. 18. ed. Campinas: Papirus, 2011. p. 59-101.

VEIGA-NETO, Alfredo. Delírios avaliatórios: o currículo desvia para a direita ou um farol para o currículo. In: FAVACHO, André Márcio Picanço; PACHECO, José Augusto; SALES, Shirlei Rezende (orgs). Currículo, conhecimento e avaliação: divergências e tensões. Curitiba: CRV, 2013. p. 155-176.

VEIGA-NETO, Alfredo. Espaço e currículo. In: LOPES, Alice Casimiro; MACEDO, Elizabeth (orgs). Disciplinas e integração curricular: histórias e políticas. Rio de Janeiro: DP\&A, 2002b. p. 201-220.

VEIGA-NETO, Alfredo. Novas geometrias para o currículo e processos identitários. In: MOREIRA, Antonio Flávio Barbosa Moreira; PACHECO, José Augusto; MACEDO, Elizabeth; CASIMIRO, Maria Alice (orgs). $O$ currículo e produção de identidades. Actas do V Colóquio sobre questões curriculares. Centro de investigação em Psicologia, Universidade do Minho, 02 a 04 de junho de 2002c. p. 13-31.

VIÑAO FRAGO, Antonio. Do espaço escolar e da escola como lugar: propostas e questões. In: VIÑAO FRAGO, Antonio; ESCOLANO, Agustín. Currículo, espaço e subjetividade: a arquitetura como programa. 2.ed. Rio de Janeiro: DP\&A, 2001. p. 60-139.

YOUNG, Michael F. D. O currículo do futuro: da nova sociologia da educação a uma teoria crítica do aprendizado. Campinas: Papirus, 2000 (Coleção Magistério: formação e trabalho pedagógico). 
Recebido em: 03/06/2017

Alterações recebidas em: 07/12/2017

Aceito em: 11/12/2017

Publicado em: 26/04/2018

44 Rev. Espaço do Currículo (online), João Pessoa, v.11, n.1, p. 29-44, jan./abr. 2018. 